\title{
Antepartum haemorrhage: causes \& its effects on mother and child: an evaluation
}

\begin{abstract}
Objective: Aim of the present study was to find the demographic profile, type of APH, maternal and perinatal complications.

Method: It is a prospective study carried out in a tertiary care hospital, Mumbai, India over a period of 2 yrs from Sept 2010 to Aug 2012 on 124 women admitted with the diagnosis of APH.

Results: The incidence of APH was $1.31 \% .73 \%$ cases of APH were associated with Pregnancy induced hypertension suggesting PIH is one of the major risk factors. Maternal and perinatal morbidity was very high with increased rates cesarean section $90 \%$, post partum hemorrhage $(36 \%)$, need of blood transfusion $(75 \%)$, preterm deliveries $(65 \%)$, low birth weight (40\%) and NICU admission (44\%). Though there is no maternal mortality due to timely intervention but 3\% patients underwent Obstetric Hysterectomy and 6.4\% required CCU admission. Perinatal mortality was very high (21\%).
\end{abstract}

Conclusion: There is very high maternal and perinatal morbidity and perinatal mortality in $\mathrm{APH}$.

Keywords: antepartum hemorrhage, maternal and perinatal morbidity and mortality
Volume 3 Issue I - 2015

\author{
Sneha Kishor Wasnik, Sachin Vijay \\ Naiknaware \\ Department of Obstetric and Gynaecology, Grant Medical \\ College and Sir JJ Group of Hospitals, India
}

Correspondence: Sachin Vijay Naiknaware, Department of Obstetric and Gynaecology, Grant Medical College and Sir JJ Group of hospitals, H. No:A- 104. Unique plaza, opposite Jakat Naka above Siddhi Vinayak, Mumbai, India, Tel 9892899579, Email:drsachinn17@yahoo.com

Received: January 21, 2015 | Published: November 5, 2015

\section{Introduction}

Complications involving the placenta, membranes, cord and foetus usually place the foetus at risk and may also increase maternal risk in the intrapartum period. Antepartum hemorrhage is one of the major complication. ${ }^{1}$

Antepartum haemorrhage is an obstetric emergency contributing to a significant amount of perinatal \& maternal morbidity and mortality. Antepartum haemorrhage is defined as bleeding from the vagina after 24 weeks. It occurs in $2-5 \%$ of pregnancies and is an important cause of fetal and maternal death. Thirty percent of maternal deaths are caused by antepartum haemorrhage of which $50 \%$ are associated with avoidable factors. ${ }^{2}$ The causes of antepartum hemorrhage can be divided into three main groups, placenta previa, placental abruption and others. Placenta previa exists when the placenta is implanted wholly or in part into the lower segment of the uterus. An abruptioplacentae is the condition whenever bleeding occurs due to premature separation of a normally sited placenta. Other causes are cervical polyp, cervical carcinoma local lesions of vagina and cervix. Systemic diseases like leukemia \& bleeding disorders are rare causes of APH. Placenta praevia and Abruptio placentae account for almost half cases of $\mathrm{APH} .^{3}$

Maternal complications of APH are malpresentation, premature labour, postpartum hemorrhage, shock, retained placenta. They also include higher rates of caesarian section, peripartum hysterectomy, coagulation failure, puerperal infections and even death. Fetal complications are premature delivery, low birth weight, intrauterine death, congenital malformations and birth asphyxia. ${ }^{4}$ In developing countries like India, women frequently experience adverse effects of obstetric haemorrhage due to widespread pre-existing anaemia, difficulties with transport and overwhelming inadequacies of maternity services. ${ }^{5}$

\section{Objectives}

The present study was conducted at a tertiary health care hospital Mumbai India. Study incidence, demographic profile, various etiological factors associated with APH and types of APH. Study maternal and perinatal outcome in APH.

\section{Material and methods}

This is a prospective study carried out over a period of two years (September 2010 to August 2012) on all the women who were admitted with a diagnosis of APH at a tertiary care institute Mumbai India There was a total of 9452 deliveries during this period and 124 women had APH. Age, parity, previous obstetric history (history of lower segment caesarean section or medical termination of pregnancy by dilation and curettage) was noted down. Records about mode of delivery, associated maternal complications such as pre-eclampsia, post partum hemorrhage, need of blood transfusion, obstetric hysterectomy and critical care unit admission, perinatal outcome in terms of maturity, birth weight, perinatal mortality, neonatal intensive care unit admission were noted and analysed. Data was presented in tables and diagrams.

\section{Results}

During the two-year study period involving 124 women with a diagnosis of APH, The following results were obtained.

\section{Maternal outcome}

The incidence APH was $1.311 \%$. Placenta previa is $0.835 \%$ and that of abruptio placentae is $0.476 \%$. The incidence of APH was $39 \%$ in the age group $26-30$ years and $22 \%$ in age more than 30 years. Seventy two percent of cases of APH were multigravida. $38 \%$ of whom were gravida $3 \&$ gravid 4 . Fifty seven cases $(46 \%)$ had a history of previous uterine surgery. Thirty three out of 45 cases of 
abruption (73\%) associated with pregnancy induced hypertension. Out of the total number of women presenting with APH (124), 75 had preterm delivery $(60.5 \%)$. Out of 124 cases who presented with APH, 112 patients $(90.32 \%)$ delivered by Caesarean section and the remaining 12 (9.68\%) delivered vaginally. In the present study, there were no mortalities. Thirty six percent were complicated by PPH. Out of total number of women presenting with APH (124), 92 required blood and blood products transfusion (75\%). For control of PPH, other operative interventions such as vessel ligation, placental bed suturing, packing of lower uterine segment were used. Caesarean hysterectomy was done in 4 cases $(3 \%)$ for intractable haemorrhage.

\section{Fetal outcome}

In this study, out of 124 women presenting with $\mathrm{APH}, 80(65 \%)$ had preterm deliveries, 50 babies $(40 \%)$ were low birth weight (below $2 \mathrm{~kg}$ ) and $39(31 \% 0$ of babies were preterm with low birth weight. There were 27 deaths $(21 \%)$, out of which $5(4 \%)$ were macerated stillbirth and $8(6 \%)$ were fresh stillbirth and $14(11 \%)$ were neonatal deaths. 17 babies (16\%) developed birth asphyxia. Out of 124 newborn babies, 54 (44\%) required neonatal intensive care unit admission due to prematurity, Low birth weight and respiratory distress (birth asphyxia). Results are shown in following charts and diagrams (Tables 1-5) (Figure 1).

Table I Incidence of APH

\begin{tabular}{ll}
\hline Total no. of cases of APH & $\mathbf{1 2 4}$ \\
\hline Placenta Previa & 79 \\
Abruptio Placentae & 45 \\
Undetermined & 0 \\
Total no of Deliveries in 2 yrs & 9452 \\
Incidence of APH & $1.31 \%$ \\
Incidence of Placenta. Previa & $0.84 \%$ \\
Incidence of Abruptio. Placentae & $0.48 \%$ \\
\hline
\end{tabular}

Table 2 Demographic parameters of women

\begin{tabular}{llll}
\hline Parameters & & Number & Percentage \\
\hline & $<20$ yrs & 10 & $8 \%$ \\
Age & $21-25$ yrs & 38 & $31 \%$ \\
& $26-30$ yrs & 48 & $39 \%$ \\
& $>30$ yrs & 28 & $23 \%$ \\
Parity & Primigravida & 35 & $28 \%$ \\
& Multigravida & 89 & $72 \%$ \\
$\begin{array}{l}\text { Associated } \\
\text { Risk }\end{array}$ & PlH (in Abruption) & & \\
Factors & $\begin{array}{l}\text { Scarred uterus (Caesarean } \\
\text { section, curettage) }\end{array}$ & $53 / 45$ & $73 \%$ \\
\hline
\end{tabular}

Table 3 Type of APH

\begin{tabular}{llll}
\hline Type of APH & & Number & Percentage \\
\hline & Type I & 13 & $11 \%$ \\
& Type II & 25 & $20 \%$ \\
Placenta Previa & Type III & 32 & $26 \%$ \\
& Type IV & 9 & $7 \%$ \\
& TOTAL & 79 & $64 \%$ \\
Abruotio Placentae & & 45 & $36 \%$ \\
Undetermined & & 0 & 0
\end{tabular}

Table 4 Baby details

\begin{tabular}{llll}
\hline Parameter & & Number & Percentage \\
\hline \multirow{4}{*}{ Maturity } & $34-36 \mathrm{wks}$ & 33 & $27 \%$ \\
& $>=37 \mathrm{wks}$ & 47 & $38 \%$ \\
& $<2 \mathrm{~kg}$ & 50 & $35 \%$ \\
Weight & $2-2.49 \mathrm{~kg}$ & 29 & $23 \%$ \\
& $2.5-3 \mathrm{~kg}$ & 32 & $26 \%$ \\
& $>3 \mathrm{~kg}$ & 13 & $11 \%$
\end{tabular}

Table 5 Maternal and perinatal complications

\begin{tabular}{llll}
\hline $\begin{array}{l}\text { Maternal } \\
\text { complications }\end{array}$ & $\begin{array}{l}\text { Number } \\
(\%)\end{array}$ & Perinatal complications & $\begin{array}{l}\text { Number } \\
(\%)\end{array}$ \\
\hline $\begin{array}{l}\text { Postpartum } \\
\text { Hemorrhage }\end{array}$ & $45(36 \%)$ & $\begin{array}{l}\text { Preterm with low birth } \\
\text { weight }\end{array}$ & $39(31 \%)$ \\
Caesarean & $112(90 \%)$ & Birth asphyxia & $17(16 \%)$ \\
Blood Transfusion & $92(75 \%)$ & Macerated still birth & $5(4 \%)$ \\
$\begin{array}{l}\text { Peripartum } \\
\text { Hysterectomy }\end{array}$ & $4(3 \%)$ & Fresh still birth & $8(6 \%)$ \\
CCU Admission & $8(6.45 \%)$ & Neonatal Deaths & $14(11 \%)$ \\
Death & 0 & $\begin{array}{l}\text { Neonatal care unit } \\
\text { admissions }\end{array}$ & $54(44 \%)$ \\
\hline
\end{tabular}

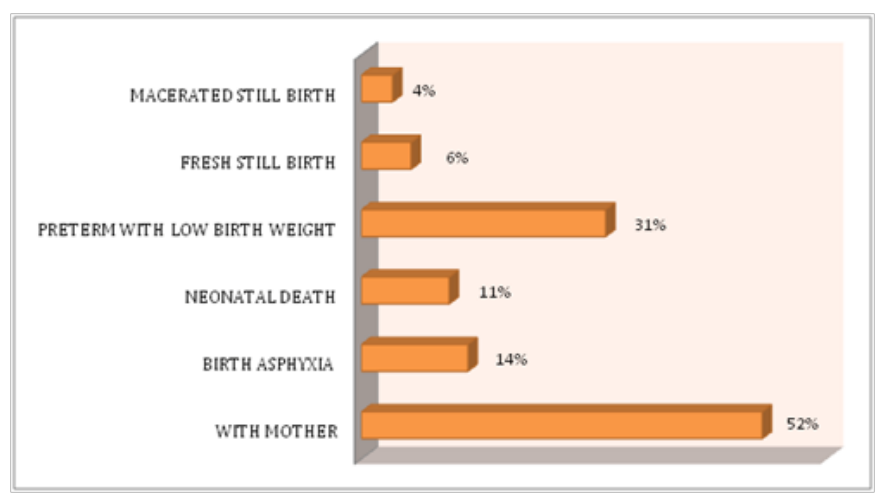

Figure I Perinatal outcome in antepartum haemorrhage. 


\section{Discussion}

The incidence of APH reported from this study is $1.311 \%$, while it is quoted to be $2-5 \%, 2.01 \%$ and $2.53 \%$ in other studies from other parts of the world. The incidence observed at Siriraj Hospital, Thailand in 1985 was found to be $0.6 \%{ }^{6}$ while Arora et al. ${ }^{7}$ from India reported the incidence of $2.53 \%$.

Mean age of patients presented with APH in this study is 26-30 years which is similar to the result reported by Das et al. ${ }^{8}$ Abbasi et al. ${ }^{9}$ also reported the mean age 30 years in a study from tertiary care hospital in Sindh. ${ }^{9}$ Incidence of APH is more in multigravida (72\%) than in primigravida (28\%) in our study. Other studies such as Gillium et al. ${ }^{10}$ and Clark et al. ${ }^{11}$ have also reported high incidence of APH in multipara which was about 5-8 times higher than primigravida thus confirming the role of endometrial damage caused by repeated childbirth, a risk factor for uteroplacental bleeding in pregnancy. Scarring of uterus due to previous uterine surgery stands out as a one of the major etiological factors for $\mathrm{APH}$, more specifically placentprevia. In the present study, 46\% (57/124) cases presented with APH had history of previous uterine surgery in the form of caesarean section, myomectomy, curettage $(61 \%$ Caesarean section (35/57), 52\% (30.57) MTPs \& check curettage following abortion). In the present study, 33 out of $45(73 \%)$ cases were associated with pregnancy induced hypertension suggesting it is one of the major risk factors for abruption resulting in APH. This is comparable to the study of Bryan et al. ${ }^{12}$ which suggested that Pre-eclampsia is an etiological factor in $80 \%$ cases of placental abruption.

The incidence of caesarean section in present study is $90 \%$. The incidence of caesarean section in placenta previa group is 100\% similar to the study done by Khouri JA \& Sultan MG. ${ }^{13}$ The incidence of caesarean in the abruption placentae group in the present study is $73 \%$ while that reported by Hurd et al. ${ }^{14}$ from the UK and the study reported by Rochelle et al. ${ }^{15}$ at Washington State were 50\% \& 37.9\% respectively. In the present study, there was no mortality. Thirty six percent of these cases were complicated by PPH. The commonest cause of PPH was uterine atony followed by coagulation failure. Crane et al. ${ }^{16}$ reported the incidence of PPH in APH to be $19 \% .{ }^{16}$ In this study $75 \%$ of patients required blood transfusion. Brenner et al. ${ }^{17}$ and William ${ }^{18}$ reported the incidence of blood transfusion as $36 \%$ and $52.4 \%$ respectively. The very high rates of blood transfusion in the present study might be due to the reason that most of the patients were already anaemic at the time of admission. Four patients (4\%) required caesarean hysterectomy and 8 patients $(6.45 \%)$ required CCU admission. Sixty five per cent of women with APH had preterm delivery in the study, this study is consistent with those of Silver et al. ${ }^{19}$ and Cotton et al..$^{20}$ who reported an association of prematurity with APH of $71 \%$ and $77.5 \%$ respectively. Forty per cent of babies were low birth weight while other authors such as Arora et al. ${ }^{7}$ and Khosla et al. ${ }^{21}$ reported $77 \%$ and $66 \%$ low birth weight respectively. Perinatal mortality was $21 \%(19 / 91)$ in the present study $(24.44 \%$ in placenta previa and $19.23 \%$ in abruptio placenta group) while Arora et al. ${ }^{7}$ and Khosla et al. ${ }^{21}$ reported very higher perinatal mortality $61.5 \%$ and $53.5 \%$ respectively. In comparison, the incidence reported by Robbins et al. ${ }^{22} 18.44 \%$. This difference may be due to advanced neonatal intensive care facility in the present institute.

\section{Conclusion}

In conclusion, there was very high maternal morbidity with increased rates of anaemia, postpartum haemorrhage, blood and blood products transfusion, caesarean section rates, preterm deliveries and prolonged post-operative stay. Similarly perinatal morbidity was high including preterm deliveries including low birth weight, birth asphyxia leading to NICU admission for variable periods. Better antenatal services, increased awareness, improved transportation; improved nutritional status can help to address some of the complications associated with antepartum haemorrhage.

\section{Acknowledgments}

None.

\section{Conflicts of interest}

The authors declare there is no conflict of interests.

\section{References}

1. John Bonnar. Massive obstetric haemorrhage. Best Practice And Research Clinical Obstetrics \& Gynaecology. 2000;14(1):1-18.

2. David A Miller. Treatment of antepartum haemorrhage. Womens and children's Hospital, Department of obstetrics and Gynaecology, Los Angeles, USA

3. Nicholas Ngeh, Amarnath Bhide. Antepartum haemorrhage. Current obstetrics \& Gynaecology. 2006;16(2):79-83.

4. Dutta DC. Antepartum hemorrhage. In: Konar HL, editor. Textbook of obstetrics. 6th edn, Kolkata, India: New central book agency; 2006:243246.

5. Harrison KA. Maternal mortality. Brt $J$ Obstet Gynecol. 1985;5(Suppl):100-115.

6. Ratnam SS, Bhaskar Rao K, Arul kumaran. Obstetrics and gynecology for post graduates. 1st edn. Chennai, India: Orient Longman Ltd; 1994;1:77-93.

7. Arora R, Devi U, Majumdar R. Perinatal morbidity and mortality in Antepartum haemorrhage. J Obstet Gynecol India. 2001;51(30):102-104.

8. Das B. Antepartum haemorrhage in three decades. J Obstet Gynaecol India. 1978;25:636-637.

9. Abbasi RM, Rizwan N, Farooq S. Fetomaternal outcome among abruption placenta cases at a University hospital of Sindh. J Liaquat Uni Med Health Sci. 2008;7(2):106-109.

10. Gilliam M, Rosenberg D, Davis F. The likelihood of placenta praevia with greater number of cesarean deliveries and higher parity. Obstet Gynecol. 2002;99(6):976-980.

11. Clark SL, Koonings PP, Phelan JP. Placenta previa/ Accreta and prior Caesarean section. Obstet Gynecol. 1985;66(1):89-92.

12. Bryan M, Hibbard. Abruptio Placentae, Pre Eclampsia, and Essential Hypertension. BJOG. 1962;69(2):282-287.

13. Khouri JA, Sultan MG. Previous Caesarean section and the rising incidence of Placenta previa and Placenta accrete. J Obstet Gynecol. 1994;14(1):14-16.

14. Hurd WW, Miodovnik M, Hertzberg V, et al. Selective management of abruptio placenta: a prospective study. Obstet Gynecol. 1983;61(4):467433.

15. Lydon-Rochelle M, Holt VL, Easterling TR, et al. First birth caesarean and placental abruption or previa at second birth. J Obstet Gynecol. 2001;97(5 Pt 1):765-769.

16. Crane JM, van den Hof MC, Dodds L, et al. Neonatal outcome with placenta previa. Obstet Gynaecol. 1999;93(4):541-544. 
17. Brenner WF, Edelman PA, Hendriches CH. Characteristics of patients with Placenta previa and results of expectant management. Am J Obstet Gynecol 1978;132(2):180-184.

18. Foote WR, Fraser WD. Placenta previa. A critical appraisal of 8 yrs of management. 1960;80:10-16.

19. Silver R, Richard D, Sabbagha RF, et al. Placenta Previa: Aggresive expected management. Am J Obstet Gynecol. 1984;150(1):15-22.
20. Cotton DB, Read JA, Paul RH, et al. Conservative aggressive management of placenta praevia. Am J Obstet Gynecol. 1980;137(6):687-695.

21. Khosla A, Dahiya V, Sangwan K, et al. Perinatal outcome in Antepartum haemorrhage. J Obstet Gynae India. 1989;9:71-73.

22. Robbins PG, Gorbach AG Jr, Reid DE. Neurologic abnormalities at one year in infants delivered after late pregnancy haemorrhage. Obstet Gynecol. 1967;29(3):358-361. 